\title{
Instrucciones para los colaboradores
}

Los colaboradores deben enviar dos copias del manuscrito, a máquina, doble espacio, y con un tamaño aproximado de 20-40 páginas; incluyendo al principio un resumen de $100-200$ palabras, y un curriculum del autor en un máximo de 100 palabras. Las notas y bibliografía (combinadas) conviene que aparezcan en hojas separadas al final del artículo, y a doble espacio igualmente. Los agradecimientos aparecerán en la primera página, en una nota no numerada, con un asterisco. El autor debe dejar clara su afiliación institucional, así como su dirección profesional. Todas las tablas o gráficos van, si es posible, en hojas separadas, y convenientemente numeradas en relación al texto; no incluir los originales del material gráfico. Los manuscritos se enviarán a la siguiente dirección:

\author{
Secretariado Ejecutivo \\ Papers: Revista de Sociología \\ Departamento de Sociología \\ Universitat Autònoma de Barcelona \\ Bellaterra, Barcelona
}

Las citas del artículo que aparezcan en las notas deben seguir el formato que se sugiere a continuación: 
J. A. Palanca, «La revolución social en medicina social», Ser 6 (1942): 11-13.

S. Aznar, «La Medicina Social y la Sociología», Revista Internacional de Sociología 15-16 (1946): 107-115.

R. Straus, «The Nature and Status of Medical Sociology», American Sociological Review 22 (1957): 202-203.

J. Díez Nicolás, «Actitudes de la mujer española hacia los métodos de planificación familiar», Revista Española de la Opinión Pública 31 (1973): 27-58.

T. Pérez de Guzmán, J. de la Cueva, y J. Herrero, «Una tipología de los médicos españoles por estratos de residencia: Rural, urbano y metropolitano», Baletín del Centro de Estudios Sociales, vol. 9, núm. 1 (1969): 5-13.

Libro:

Pedro Laín Entralgo, La relación médico-enfermo, 3. ${ }^{a}$ ed. (Madrid: Revista de Occidente, 1964), p. 27.

Fundación FOESSA, Informe sociológico sobre la situación social de España (Madrid: Euramérica, 1970), pp. 751-831.

World Health Organization, Regional Office for Europe, The Social Sciences in Medical Education (Copenhague: WHO, 1970), p. 6.

José M. López Piñero, y Luis García Ballester, Introducción a la medicina (Barcelona: Ariel, 1971).

Félix Martí-Ibáñez, comp., Henry E. Sigerist on the History of Medicine (Nueva York: MD, 1960).

José Ros Jimeno et al., Estudios demográficos (Madrid: Consejo Superior de Investigaciones Científicas, 1945).

Capítulo de un libro:

Nicolás Caparrós, «Introducción a la antipsiquiatría», pp. 9-27 en H. Heyward, y M. Varigas, Anti-Psiquiatría: Una controversia sobre la locura (Madrid: Fundamentos, 1972).

Antonio Gallego, «Spain», pp. 77-86 en E. Purcell, comp., World Trends in Medical Education (Baltimore: 'The Johns Hopkins Press, 1971), p. 81 . 
Instrucciones

Manuscrito no publicado:

FRAP, «Financiación de la Seguridad Social» (Documento policopiado, Madrid, 1974), p. 3.

José M. López-Cepero et al., «Encuesta sobre la profesionalidad médica en España», mimeografiado (Madrid: Comisión Nacional Española del Instituto Internacional de Estudios de Clases Medias, 1960). 